Artigos 


\section{Lógicas y concepciones sobre trabajo, acumulación y bienestar en los pueblos de indios guaraníes (Siglos XVII y XVIII)}

Lía Quarleri*

Resumen: En el presente trabajo se busca analizar, a partir del estudio de las poblaciones guaraníes, reducidas en misiones jesuitas y más tarde en pueblos de indios, cómo se fueron imponiendo o se buscaron imponer reestructuraciones en las prácticas cotidianas en relación a las modalidades y medios de explotación y circulación de los recursos en intima relación con las concepciones europeas sobre trabajo, ocio, productividad y bienestar. Se busca analizar la configuración de tres grandes modelos e imaginarios, el primer de ellos centrado en la oposición desierto/abundancia, sostenido como variable en los primeros tiempos jesuíticos; el segundo enfocado en el cambio de una economía de reciprocidad a la de un intercambio de bienes controlado bajo el sistema reduccional y el último en los contraste surgidos entre el sistema de comunidad y el régimen de libertad económica, en las últimas décadas del gobierno colonial. Para ello se citarán cronistas españoles, jesuitas y a funcionarios borbónicos, haciendo hincapié en las tensiones, transformaciones y en las respuestas estratégicas como mecanismos de adaptación y resistencia de las familias guaraníes.

Palabras clave: Misiones guaraníes. Economía indígena. Río de la Plata

\footnotetext{
* Doctora en Antropología Social por la Universidad de Buenos Aires. Investigadora Adjunta del Consejo Nacional de Investigaciones Científicas y Técnicas (CONICET). Docente del Instituto de Altos Estudios Sociales (IDAES), Universidad Nacional de San Martín (UNSAM) y de la Universidad de Buenos Aires (UBA). Dirección de correo electrónico: liaquarleri@yahoo.com.ar.
}

Anos 90, Porto Alegre, v. 20, n. 37, p. 177-212, jul. 2013 
En la historia de América Latina desde la conquista europea hasta nuestros días diferentes fenómenos fueron punteando transformaciones a diferentes niveles en relación con la explotación de recursos, el medio ambiente, las labores productivas o extractivas ejercidas a expensas de las poblaciones indígenas locales y su espacio circundante. Desde la conquista se buscó imponer un conjunto de prácticas de tradición ibérica en torno a la producción, la tributación, la división social, étnica y sexual de las tareas cotidianas, la acumulación de excedentes y la circulación de bienes. Estas fueron respaldadas por concepciones y argumentaciones que fueron tejiendo redes ideológicas que justificaron acciones y normativas por parte de las autoridades coloniales. Si bien estas afirmaciones no constituyen novedades teóricas, la referencia al nivel de los imaginarios, las concepciones y los discursos no han acompañado siempre con debida equidad las reflexiones en torno a los mecanismos de dominación ejercidos en función de los aspectos mencionados. Al respecto consideramos la importancia de analizar los procesos históricos y sociales teniendo en cuenta tanto la tela conceptual e ideológica como los mecanismos más visibles de implementación de relaciones de poder y dominación. Esta doble vertiente ha caracterizado a las interacciones coloniales tanto en los ámbitos religiosos, como sociales y económicos. En este último nivel se han destacado las argumentaciones, desde el lado de las elites coloniales, en torno a lógicas europeas de trabajo, acumulación y comercialización desacreditando o ignorando las tradiciones locales y los sentidos culturales dados a las mismas. Sin embargo, estos intentos de desplazar las prácticas indígenas no deben ser entendidos sin aludir al mismo tiempo a las respuestas y adaptaciones locales, que pusieron resistencia o amalgamaron artilugios de dominación e imposición de lógicas y reglas de juego sin consenso, persiguiendo intereses y objetivos sectoriales por parte de las elites hispano-criollas, los administradores coloniales y los agentes de gobierno metropolitanos.

Dentro de la América hispánica, transcurrida la etapa de conquista insultar, diferentes modalidades de tributo, trabajo y explotación de la tierra se fueron implementando bajo la genérica institución de la encomienda. Si bien la literatura más crítica, surgida durante las décadas de 1960 y 1970, ha mostrado las consecuencias más profundas a 
nivel demográfico, económico, político y cultural del fenómeno de la conquista y en particular de la encomienda, los repartimientos y las prestaciones de trabajo en general, desde los años 80 del siglo XX se buscó por un lado entender las diferencias situacionales y regionales y por el otro lado analizar las respuestas indígenas, bajo la nueva vertiente teórica de la agencia asignada a sectores que hasta entonces no habían sido interpelados por la historiografía o la teoría social ${ }^{1}$. Dentro de este marco, tanto los conceptos de resistencia, adaptación, adaptación en resistencia, negociación, alianzas interétnicas traspasaron el estudio de diferentes aspectos del mundo colonial y en especial a aquellos vinculados con la tenencia de la tierra, la explotación productiva y las exigencias fiscales. No han sido pocos los estudios que han analizado los imaginarios culturales y sus imbricaciones dentro de políticas oficiales, como por ejemplo las reformas borbónicas, en los movimientos de rebelión o resistencia indígena o campesina o en los levantamientos urbanos, de mestizos o comuneros. En los últimos años, las investigaciones que abordaron el mestizaje, los procesos de hibridación, sincretismo o etnogenesis, según las épocas y las corrientes teóricas, han puesto la mirada o el eje en otros temas, destacándose la religión, el arte y la circulación e intercambio de bienes, ideas y personas, con el fin de registrar las dinámicas de las interacciones y la conexión entre espacios distantes ${ }^{2}$. Finalmente, los diferentes enfoques mencionados fueron alimentando una mirada más compleja en el devenir de la colonización americana y su especificidad regional e histórica en función de características puntuales y de respuestas locales.

En el presente trabajo se busca analizar, a partir del estudio de las poblaciones guaraníes, reducidas en misiones jesuitas y más tarde en pueblos de indios, cómo se fueron imponiendo o se buscaron imponer reestructuraciones en las prácticas cotidianas en relación a las modalidades y medios de explotación y circulación de los recursos en intima relación con las concepciones europeas sobre trabajo, ocio, productividad y bienestar. La conformación de núcleos de residencia para la evangelización, producción y acopio de recursos, con población indígena, partía de tradiciones previas acomodadas y ajustadas a los objetivos de las empresas de conquista y colonización. Como parte de ellas se fueron desplegando 
nuevos mecanismos de exacción tributaria, distribución de tareas y exigencias productivas, entre las poblaciones reducidas, que en algunos casos se alimentaron sobre variables locales y en otros casos buscaron desplazarlas ignorando prácticas, tradiciones y lógicas subyacentes. Este fenómeno quedó ilustrado por ejemplo con la imposición, aunque con matices, de una economía de mercado, sobre una tradicional economía de reciprocidad, con sus especificidades, adaptaciones y resistencias por parte de las poblaciones locales. En el caso de las poblaciones guaraníes estudiadas esta política de desplazamiento tuvo sus características propias en virtud de que en un primer momento estuvo liderado por los jesuitas y luego, tras la expulsión de aquellos, por funcionarios coloniales con particulares concepciones sobre el destino de los pueblos, la mano de obra, el comercio y la educación. En nuestro interés mostrar las diferentes etapas en la que discurrieron estos cambios, las adaptaciones locales y las concepciones que guiaron las mismas con el fin de mostrar las vinculaciones entre política e ideológica en relación a los ejes mencionados.

En relación al espacio guaraní-misionero, no son pocos los trabajos que han estudiado el régimen misionero antes y después de las expulsión de los jesuitas abarcando las dimensiones económicas, patrimoniales, demográficas, administrativas y geopolíticas, aunque en menor medida. En lo que hace a los aspectos económicos no pueden dejar de mencionarse para el caso de las reducciones jesuíticas los trabajos de Arnaldo Bruxel (1959), Rafael Carbonell de Masy (1992 a y b), José Otávio Catafesto de Souza (2002), Pablo Hernández (1913), Guillermo Furlong (1962), Regina Gadelha (1980), Juan Carlos Garavaglia (1984 y 1987), Norberto Levinton (2006), Ernesto Maeder (1997), Bartomeú Melíá (1987 y 1996), Bartomeú Melía y Dominique Temple (2004), Magnus Mörner (1986), Eduardo Neumann (1996), Oreste Popescu (1967), Branislava Susnik (1984) y Guillermo Wilde (2001a), básicamente. Finalmente, en relación al espacio guaraní-misionero, no son pocos los trabajos que han estudiado el régimen misionero después de las expulsión de los jesuitas abarcando las dimensiones económicas, patrimoniales, demográficas, administrativas y en menor medida geopolíticas (HERNÁNDEZ, 1999 y 2002; MAEDER, 1992; POETNIZ;

Anos 90, Porto Alegre, v. 20, n. 37, p. 177-212, jul. 2013 
POETNIZ, 1998; SANTOS; BAPTISTA, 2007; SARREAL, 2008 y 2011; SUSNIK, 1966; WILDE, 2001b y 2009), para citar solo algunos autores). Todos estos trabajos han contribuido desde diferentes líneas a desasnar las variables del modelo jesuítico y del sistema de administración erigido tras la expulsión, así como las consecuencias que para los pueblos guaraníes fueron teniendo cada uno de estos regimenes. En el presente trabajo retomamos ciertos elementos ya trabajados en estos estudios para focalizar la reflexión en torno a las políticas económicas y a las concepciones subyacentes o explícitas que fueron sustentando y argumentando las mismas desde el lado de los agentes coloniales, desde los jesuitas hasta los funcionarios borbónicos. Se busca analizar la configuración de tres grandes modelos e imaginarios en relación a los pueblos guaraníes, el primer de ellos centrado en la oposición desierto/abundancia, sostenido como variable en los primeros tiempos jesuíticos; el segundo enfocado en el cambio de una economía de reciprocidad a la de un intercambio de bienes controlado bajo el sistema reduccional y el último en los contraste surgidos entre el sistema de comunidad y el régimen de libertad económica, en las últimas décadas del gobierno colonial. Tras la presentación de los modelos históricos se apelará a cronistas españoles, jesuitas y a funcionarios borbónicos para dar cuenta de las políticas y los imaginarios que sustentaron las mismas, haciendo hincapié en las tensiones, transformaciones y en las respuestas estratégicas como mecanismos de adaptación y resistencia de las familias guaraníes.

\section{La abundancia guaraní en las crónicas tempranas}

La conformación de reducciones jesuíticas con población de origen guaraní, hacia principios del siglo XVI, se produjo en un contexto de intensa rivalidad bélica entre estos grupos y los portugueses aliados a los tupíes y a las autoridades civiles y eclesiásticas lusitanas, como así también de avance de los colonos españoles sobre las poblaciones locales con el objeto de sumar réditos de las encomiendas. Esta situación planteó desde su origen una paradoja histórica centrada en la conformación de alianzas de intereses contrapuestos, 
entre caciques indígenas y misioneros jesuitas con la consiguiente canalización de recursos y energía de las aldeas indígenas. De esta forma, en sintonía con otras alianzas hispano-indígenas suscitadas en otros contextos coloniales tempranos, lo que implicaba desde el lado de los jefes étnicos y sus comunidades la posibilidad de sostener o defender cierto estado de situación en relación a la organización política y económica, desde el lado de los jesuitas solo era pensado como el comienzo de un conjunto pautado de transformaciones en todos los niveles. Esto quedó expresado de diferente forma y en diferente grado en todos los cronistas jesuitas desde Ruiz de Montoya hasta Manuel Peramás así como en las Cartas Anuas escrita por los provinciales y otros administradores jesuitas ${ }^{3}$.

Más allá de la cuestión religiosa, ampliamente estudiada por la historiografía especializa, los primeros misioneros se propusieron revertir modalidades de relación de los guaraníes con el medio natural y sus recursos, no contempladas como satisfactorias a los fines de un plan general de "civilización". En esta línea no se manifestó una intención por comprender y menos aceptar la cultura selvática guaraní, basada en una economía de reciprocidad y en una relación holística con el entorno próximo y distante. En este cruce de modelos y en sus consecuencias es que se plantearon grandes incongruencias derivadas de este pacto inicial. Al respecto, la disposición de tierras, recursos y de una economía agrícola fue la base para que los primeros colonizadores del Río de la Plata fundaran Asunción, sobre el Paraguay en territorio habitado por los carios guaraníes, y para que los jesuitas tiempo después erigieran reducciones sobre los ríos Paraná y Uruguay. La colaboración política inicial por parte de los guaraníes hacia los conquistadores y misioneros tuvo como eje la redistribución posterior de los recursos comunales para fines concretos y extemporáneos. Si bien en el caso de los pueblos de indios que quedaron bajo jurisdicción de los colonizadores y encomenderos las trasformaciones fueron en cierto sentido más profundas, desde lo económico y socio/político, ambos proyectos desconocieron la lógica económica que sustentaba aquel "bienestar" que había convocado a conquistadores y misioneros a desplegar sus afanes colonizadores y evangelizadores en aquellas tierras hasta ese momentos controladas por los aguerridos guaraníes.

Anos 90, Porto Alegre, v. 20, n. 37, p. 177-212, jul. 2013 
La presencia dominante de estos grupos en la región les había permitido ocupar extensas áreas fértiles a lo largo de los ríos Paraguay, Paraná y Uruguay. Los guaraníes eran expertos en la colonización de la selva y en la agricultura de roza y quema que exigía el uso de amplios territorios así como la rotación periódica para evitar el desgaste. Su dieta alimenticia era variada en cultivos y en recursos obtenidos a través de la recolección, la caza y la pesca. Dicha diversidad conllevaba la necesidad de desplegarse sin fuertes limitaciones, aunque con restricciones, en un continuo que iba desde la aldea, la huerta hasta el monte (CHAMORRO, 2004). El espacio habitable, denominado Tekoa, era expresión de la interrelación equilibrada del universo físico/social. La variable opuesta implicaba la existencia del mal en la tierra y la necesidad de emprender la búsqueda de nuevos horizontes, liderada por los jefes políticos y religiosos. Dentro de esta cosmología se consideraba que era en virtud de la "vida en la tierra", una "tierra humanizada", que se lograba el bienestar y la perfección de la vida social (MELIÁ; TEMPLE, 2004, p. $23)^{4}$. La relación con el entorno material, vegetal y animal era concebida de forma íntima e inclusiva y, en este sentido, no existía un concepto de bien material o recurso natural en sus términos más teleológicos o utilitarios tal como era sostenido dentro de la tradición occidental que portaban los conquistadores. Sin embargo, no era que las acciones o relaciones en torno al medio ambiente y sus recursos no tuviesen fines concretos o sentidos compartidos sino que estos entraban dentro de una lógica diferente a la estipulada dentro del esquema de pensamiento occidental. Los guaraníes interactuaban dentro de un universo de cosas y seres interrelacionado por redes de significación y praxis mágico-religiosas y era en virtud de este entrelazado de cosmovisiones que abordaban el acceso a los bienes alimenticios, curativos o rituales.

La distinción entre naturaleza y sociedad, profundizada con la modernidad occidental, en sus diferentes etapas, no tenía entre las poblaciones guaraníes un reflejo análogo, incluso a vistas de los europeos. Por el contrario, en la cosmología de estos grupos que habitaban extensos territorios sobre importantes vías fluviales, no existía tal distinción, cuestión que quedaba manifestado en sus prácticas cotidianas y en su mitología. Lo que primaba entonces 
era una perspectiva relacional que se articulaba con tradiciones de pensamiento de otros grupos, en particular aquellos de origen amazónico. A diferencia de la tradición occidental, “[...] la concepción amerindia supondría, por el contrario, una unidad del espíritus y una diversidad de los cuerpos. La cultura o el sujeto serian aquí la forma de lo universal, la naturaleza o el objeto, la forma de los particular" (VIVEIROS DE CASTRO, 2004, p. 38). En este sentido, más allá de las especificidades culturales lo que se destacaba en esta tradición de pensamiento era la creencia en que todos los seres animados poseían una esencia antropomorfa de tipo espiritual en donde los cuerpos eran solo apariencias variables, situacionales e intercambiables. Naturaleza y cultura, eran parte, a su vez, de un mismo universo socio/cósmico.

Entre los guaraníes, el acopio de ciertos bienes y su consumo estaban en íntima relación con la idea de bienestar sostenida por estas comunidades, asociado a la búsqueda de un equilibrio constante, cuya máxima expresión eran las fiestas y los banquetes rituales. Si bien existían ciclos de abundancia y escasez alimenticia, la búsqueda de un estado de bienestar era permanente y las etapas de menor disposición de alimentos o de crisis diversas se vivían como el paso necesario para reorientar las energías hacia las instancias siguientes, alimentadas por concepciones mágico-religiosas actualizadas por sus líderes. Este entramado de prácticas y concepciones les había permitido a ciertas parcialidades guaraníes controlar importantes extensiones de tierras de cultivo. La concentración de tierras fértiles en cabeza de ciertas comunidades fue evidenciada por los europeos en sus primeros contactos con los carios guaraníes del Paraguay. Esta situación daba cuenta de que estas sociedades de cultura de floresta y de origen amazónico habían logrado desarrollar mecanismos políticos relativamente eficientes a los fines de generar congregaciones eventuales de aldeas y con ellos de espacios circundantes potencialmente afines a la agricultura, la caza y la pesca.

No obstante, la búsqueda de tierras y la defensa de sus núcleos de asentamiento formaban parte de estrategias o tácticas evaluadas dentro de un universo conceptual propio. Al respecto, si bien la acumulación de recursos y las técnicas de conservación de 
alimentos perecederos para tiempos difíciles o para el intercambio con grupos externos estaban en teoría ausentes o no se destacaban dentro de las tradiciones de estos grupos, esto no implicaba la falta por completo de una lógica económica. Por el contrario, esta existía pero asociada a redes conceptuales propias y en íntima relación con otras dimensiones socio-religiosas y políticas ${ }^{5}$. La dimensión económica no era entendida como un aspecto autónomo dentro de la vida social, como en el caso de la tradición occidental. Pese a de ello si existía un sistema de organización para los fines de subsistencia, consumo y distribución de bienes. La diferencia central estaba dada porque mientras los conquistadores imbuidos por afanes y utopías múltiples de enriquecimiento, prestigio y evangelización perseguían la acumulación de bienes o metales, los guaraníes consumían ampliamente los recursos alimenticios obtenidos o cultivados en fiestas rituales donde se ponía en juego la generosidad de los líderes, el bienestar de la comunidad y el deleite grupal.

De esta forma, el bienestar comunal era medido desde una óptica diferente a la de los conquistadores y misioneros. Con todo, estas perspectivas nos fueron uniformes, por el contrario fueron variando según las etapas de conquista, las regiones y los observadores. En este sentido, las motivaciones puntuales y las situaciones influyeron en las miradas que diferentes sujetos o agentes coloniales dejaron registradas sobre las adjetivaciones socio/económicas de los grupos locales. Esto último quedó ilustrado diversamente en las crónicas e historias escritas por conquistadores o misioneros. Así mientras estos últimos pusieron el acento en demostrar la ausencia de prácticas o creencias consideradas positivas, como eje del proceso de conversión, los primeros conquistadores describieron o elaboraron sus narrativas desde la necesidad de traducir lo observado a un universo mental conocido. Este fue el caso de Ulrico Schmidl donde la disposición de bienes, traducido por el en "abundancia", lo llevó a reparar en los carios guaraníes.

Este esquema de intereses y necesidades determinó que fuera con los carios guaraníes con quienes los primeros conquistadores del Río de la Plata tuvieron mayor contacto y relación. Al respecto, al mencionar los motivos que determinaron esto último Schmidl afirmó que "[...] la gente y la tierra nos parecieron muy convenientes, especialmente los alimentos" (SCHMIDL [1567], 1997, p. 45).

Anos 90, Porto Alegre, v. 20, n. 37, p. 177-212, jul. 2013 
Desde la perspectiva de este soldado alemán que llegó al Río de la Plata en la tripulación de Pedro de Mendoza los guaraníes poseían todo lo que ellos necesitaban, alimentos, mujeres y guerreros. En este marco no se impuso un desconocimiento de la potencialidades de la región y de la supuesta disposición de su gente, lejos de ello se reconoció que "[...] cada cinco leguas de camino [...]" hallaron "[...] una aldea de los carios [...]" y que estos les proporcionaran "[...] en cada ocasión” [...] “[...] alimentos, pescados y carne, gallinas, gansos, ovejas indias, avestruces y otras cosas más de lo que nosotros los cristianos precisábamos [...]" (SCHMIDL, [1567] 1997, p. 50-51). Así la clara conciencia de que aquellos poseían alimentos y bienes necesarios para su supervivencia constituyó la base de una relación que cobró la forma de alianza y luego de abuso y que se asentó sobre la estimación especulativa de los recursos humanos y materiales de estas sociedades.

En el Río de la Plata, en torno a la primitiva Asunción, la capacidad de organización de los guaraníes fue canalizada en beneficio de los primeros colonizadores quienes supieron sacar réditos de las lógicas políticas del cuñadazgo desplegada entre estos grupos como forma de entablar alianzas entre líderes próximos o distantes. Como parte de estas alianzas los jefes étnicos obtuvieron el apoyo militar y simbólico contra sus históricos enemigos, los payaguas, y los españoles se beneficiaron de la concesión de bienes y mujeres, como parte de los mecanismos de reciprocidad ${ }^{6}$. Sin embargo, poco después quedaron expuestos los intereses contrapuestos o incompatibles entre unos y otros y con ello los alcances de este pacto inicial. Tanto las significaciones y entramados culturales diferenciales como la propia dinámica que fue tomando la conquista pusieron en tela de juicio la continuidad del intercambio generado en los primeros tiempos. Desde el lado de los europeos la conformación de relaciones jerárquicas y estratificadas incluso con sociedades respetadas por sus baluartes guerreros formaba parte de profundas y antiguas tradiciones bélicas ejercidas durante la reconquista ibérica y la conformación de señoríos locales a expensas de tierras y personas. Por otra parte, la política de tributación entre sectores sociales diferentes estaba en vigencia en la sociedad ibérica de la conquista europeo y en su lógica asimétrica y jerárquica

Anos 90, Porto Alegre, v. 20, n. 37, p. 177-212, jul. 2013 
fue impuesta extensamente, con adaptaciones locales, a partir de la encomienda y el servicio personal ${ }^{7}$.

En el caso de los pueblos guaraníes la imposición del sistema de encomiendas, a partir de la década de 1550, asignó un límite a la relación política previamente entablada al mostrar las diferencias con las relaciones reciprocitarias en sus aspectos más simbólicos como cotidianos. Como parte de la economía del Don la circulación debía ser constante y no agotarse desde el punto de vista de los lazos políticos y familiares por el sobre uso o abuso de algunas de las partes involucradas en la relación. Si bien, los guaraníes como sociedades en donde la guerra cumplía un rol fundamental en la consolidación y extensión como en la cohesión grupal, contemplaba la incorporación de "esclavos" como parte del botín de guerra dentro de la estructura societaria, la presencia de los europeos planteó otros desafíos bélicos y políticos que no pudieron ser afrontados por los medios usuales de rivalidad y venganza tradicionales. La relación de desigualdad y hasta desventaja evidencia a los pocos años de la conquista mostró entonces las aristas negativas de la nueva situación. Asimismo, en la economía guaraní como parte de las economías basadas en la producción doméstica las exigencias propias de la encomienda y el servicio personal produjeron un impacto en los mecanismos de reproducción social al requerir la producción de excedentes más allá del núcleo doméstico y de la familia extensa ${ }^{8}$.

Hacia fines del siglo XVI la situación de los guaraníes próximos a las aldeas españolas había cambiado extensamente ya que los conquistadores habían desviado las potencialidades productivas de estas sociedades para fines exógenos a las mismas. Aquellos observadores atentos no podían ver más que desestabilización y crisis al considerar también las propias reacciones de resistencia y rebelión que se fueron suscitando en el antiguo Paraguay como respuesta a las consecuencias y transformaciones desencadenadas por las encomiendas y luego por la acción de los franciscanos en los nuevos pueblos de indios (NECKER, 1990; ROULET, 1993). Sobre este contexto, sumado a las presiones ejercidas por los luso/ brasileros esclavistas es que actuaron con relativo éxito los jesuitas, erigiendo misiones en áreas en su mayoría aún no afectadas por la 
colonización y la encomienda. Sin embargo, el sustento ideológico que constituyó la base legitimadora de este nuevo proceso de colonización se alimentó de la construcción de una alteridad negativa en torno a aquellos grupos sujetos potenciales de conversión y en ese proceso cobró fuerza no solo las sentencias en contra a los cultos y prácticas guaraníes de orden mágico/religioso sino también y en especial aquellas que los mostraba en un supuesto estado de naturaleza sin artilugios culturales. Desde esta óptica, los guaraníes como otros grupos, en su estado de naturaleza solo eran proclives a las fuerzas demoníacas que actuaban para alejarlos de la salvación, según los jesuitas, solo obtenida a través del manto de Dios cristiano.

\section{De la economía de reciprocidad al intercambio controlado}

Entre los cronistas jesuitas que participaron del proceso de conformación de reducciones guaraníes en los ríos Paraná y Uruguay fue Antonio Ruiz de Montoya uno de los más renombrados por la historiografía especializada. Este jesuita a través de su obra La Conquista espiritual del Paraguay (1639), dejó asentada además de una historia de la misionalización jesuita en la región, un conjunto de variadas representaciones sobre los condicionantes y potencialidad geográficas de la misma y de sus habitantes los guaraníes en una fotografía sobre lo que entendía como la represtación acabada del hombre en estado de naturaleza. En su relato Montoya relacionaba la condición de los guaraníes con la de una barbarie peyorativa y peligrosa, por la acción diabólica que había corrompido y corrompía, según este misionero, la naturaleza de estas tierras en casi todas sus formas. Para caracterizar y nominar a la misma y a sus habitantes, Montoya hizo uso reiterado de la categoría "naturales" y remitió al entorno como una alegoría de un "desierto" despojado de las artes de la vida en sociedad. Para reforzar esta imagen introdujo su obra con una descripción sobre las dificultades y hazañas de sus travesías desde una intensa alusión a las mismas. Al respecto, Montoya contaba que había vivido: 
[...] todo el tiempo dicho en la provincia del Paraguay y como en el desierto, en busca de fieras, de indios bárbaros, atravesando campos y trasegando montes en busca suya para agregarlos al aprisco de la iglesia santa y al servicio de Su Majestad, de que con mis compañeros hice trece reducciones o poblaciones, con el afán, hambre, desnudez y peligros frecuentes de la vida que la imaginación no alcanza, en cuyo ejercicio me parecía estar en el desierto [...] caminando al pie de dos mil leguas, con el peligro y riesgo de mar, ríos y enemigos que es notorio, a pedir instantemente el remedio de tantos males que amenazan muy grandes estorbos de su real servicio, y dijera mejor, daños y peligros de perderse la mejor joya de su corona real (RUIZ DE MONTOYA [1639], 1989, p. 46-47).

En respuesta a tal panorama inicial es que, según Montoya, los jesuitas organizaron poblaciones entre los guaraníes como un acto político fundante de una nueva sociedad en donde antes solo había barbarie y donde la naturaleza en su estado más adverso dominaba casi plenamente. Con el paso del tiempo Montoya encontró en los pueblos reducidos aliados para continuar su insistente tarea de convertir a los otros y sumarlos a su causa a través de medios que reproducían aquellos utilizados supuestamente por los hombres que vivían en un despreciable estado de naturaleza. Montoya en su "Conquista Espiritual" relataba como los indios "[...] ya bien fundados en la fe, (servían) de cazadores para juntar estos rebaños. Y este que hoy rebelde corre por los bosques, ya manso mañana, ayuda a nuestros padres a rastrear otros, y a sí se va continuando la espiritual conquista”. Mientras quienes no vivían "ajustados a la ley divina" quedaban expuestos a los "diabólicos embustes" por medio de una "[...] naturaleza deleznable ayudada de la paz, comidas y descanso y olvidad de tan conocido azote [...]" que hacían los temibles tigres "como instrumentos de la justicia divina" cuando los indios reducidos abandonaban el camino de la fe (RUIZ DE MONTOYA (1639), 1989, p. 235-238). Bajo este manto de amplias condenas y dogmas absolutos los jesuitas emprendieran su colonización religiosa que implicó una política de trasformación de prácticas y sentidos. $\mathrm{Al}$ respecto, la vida

Anos 90, Porto Alegre, v. 20, n. 37, p. 177-212, jul. 2013 
en las reducciones significó en teoría una pérdida de privilegios y costumbres como la poligamia y la antropofagia; la sumisión a nuevas prácticas, como el castigo corporal y el tormento espiritual; la adopción de ritmos cotidianos asociados al culto cristiano y a la economía, al adiestramiento en oficios artesanales y militares, la convivencia en espacios cerrados; la parcelación de los cultivos, el acopio de recursos y la imposición de limitaciones y controles sobre la movilidad física; la relación con el otro, la sexualidad e incluso la alimentación.

En lo que hace específicamente a la organización económica la historiografía especializada ha hecho hincapié en la intersección de viejos y nuevos modelos económicos. Sobre la base de la producción doméstica nuclear los jesuitas recrearon dos niveles de organización de la tenencia de la tierra, el trabajo, el acopio de recursos, el acceso y distribución de los mismos, denominados abambaé y el tupambaé, respectivamente. El primero consistía en una reinterpretación jesuita de las tradiciones guaraníes y se centraba en el trabajo familiar en una pequeña parcela, con el fin de garantizar la subsistencia doméstica a través del cultivo de maíz, legumbres y mandioca. El trabajo en el tupambaé, conjunto de tierras de la comunidad o del pueblo, era realizado por diferentes familias o parcialidades y estaba destinado específicamente a la obtención de bienes para almacenar o satisfacer necesidades diversas relacionadas con eventos rituales, situaciones extraordinarias, como podían ser sequías o epidemias y con el mantenimiento de la administración político/religiosa de las reducciones. Esto último era garantizado, en general, a través de los réditos de la comercialización de estos bienes bajo el control de los misioneros (GARAVAGLIA, 1987). Ambos tipos de modelos de producción, distribución y consumo respondían a ciertas prácticas familiares y comunales de acceso a los recursos observadas entre los guaraníes pero reorientadas con el fin de alcanzar niveles de eficiencia, acumulación y bienestar asociados a la política de estratificación colonial, de misionalización jesuita y de racionalidad económica occidental.

A lo largo de los siglos XVII y XVIII, las reducciones jesuitas de guaraníes alcanzaron un grado de desarrollo notable, a juicio de sus contemporáneos, en virtud de la cantidad de población que habitaba las mismas, la capacidad de reproducción frente a las crisis 
y el alto nivel de productividad y comercialización, en comparación con otros productores (MÖRNER, 1986). En lo que hace a las reducciones los niveles de productividad, si bien fueron importantes como para motivar una sólida inserción en el mercado regional, no siempre cumplieron con las expectativas esperadas y con las necesidades surgidas frente a las exigencias de la propia dinámica de expansión de la Compañía de Jesús en la región?. Desde el lado de los jesuitas los juicios de desajuste entre expectativas y resultados se debían a la falta de adaptación o al propio temperamento de los guaraníes que determinaba en teoría la ausencia de comportamientos económicos adecuados. Dentro de este esquema, se hizo hincapié en la ausencia de aptitudes para el trabajo, la producción de excedentes y la acumulación de bienes y por ende de la capacidad para el bienestar comunal. Al mismo tiempo se remarcó insistentemente en el uso del tiempo de forma improductiva, denominado ocio, al intercambio sin medida o mensura y a la ausencia de previsión. Entre aquellos misioneros y cronistas que dejaron testimonio de estas concepciones en torno al trabajo de los guaraníes reducidos se encuentran los padres Antonio Sepp y José Cardiel. El primero de ellos, desde las reducciones escribía en relación al trabajo agrícola lo siguiente:

Siendo tan fértil el suelo, no se les ocurría a estos indios, por flojos el cultivarlo, sino, como en todo lo demás, se les había de obligar a ello, amenazándoles con darles azotes. Además, hago cultivar para mi y mis enfermos unas 40 hasta 50 cuadras de trigo; pero hay que fijarse bien para que no lo coman estando todavía en grano [...] Como los indios son incapaces de toda economía y previsión, cumpliéndose en ellos a la letra la palabra de Cristo: 'no os congojéis por el día de mañana', es menester que el mismo Padre, tenga, como tiene, graneros y almacenes, para recoger y repartir a su tiempo la cosecha, y guarde lo necesario para la siembra futura (SEPP, [1732] 1962, p. 30).

En la misma línea, desde el exilio recordando los tiempos misioneros José Cardiel relataba que: 
Con cuatro semanas efectivas que trabajan, tienen bastante para lograr el sustento para todo el año, como sucede con los más capaces y trabajadores, porque la tierra es fértil; pero generalmente es tanta la desidia del indio, que, atenta ella, es menester todo este tiempo. Y con todo eso, el mayor trabajo que tienen los curas es hacerles que siembren y labren lo necesario para todo el año para su familia; y es menester con muchos usar el castigo para que lo hagan, siendo para solo su bien, y no para el común el pueblo. Procuraran los Curas visitar con frecuencia sus sementeras, y envían indios fieles que les de den cuenta de ellas. Algunos curas hacen medir con un cordel lo que les parece suficiente para el sustento anual de su casa: y les imponen pena de tantos azotes, sino labran todo: porque el indio es muy amigo de poquitos por su cortos espíritus, y su vista intelectual no alcanza hasta fin de año, ni le hacen fuerza las razones, ni la experiencia del hambre que sintió el año antecedente por haber sembrado poco. Otros padres les hacen labrar y escardillar la tierra por junto, todos los de un cacique o de una parcialidad juntos: hay tantas sementeras y mañana otras tantas, con un espía como censor o contador, que les haga hacer su deber, además de los caciques y mayorales: que les cuente, y de razón de todo al Cura; y con todo este cuidado no se suele conseguir que cojan lo necesario (CARDIEL, [1771] 1994, p. 49).

En relación a las formas de consumo Cardiel y a las necesidades de direccionar el mismo mencionaba:

Ni basta el hacerle coger toda su cosecha. Lo más que cogerá un indio ordinario es tres o cuatro fanegas de maíz. Bien pudiera coger veinte, si quisiera. Si esto lo tiene en su casa, desperdicia mucho, y lo gasta luego, ya comiendo sin regla, ya dándole de balde, ya vendiéndolo por una bagatela, lo que vale diez por lo que vale uno. Por eso se lo obliga a traerlo a los graneros comunes, cada saco con su nombre: y se le deja uno solo en su casa y se le va dando conforme se le va acabando. Toda esta diligencia es necesaria para su desidia.

Anos 90, Porto Alegre, v. 20, n. 37, p. 177-212, jul. 2013 
Estas cosas con otras de economía temporal cuestan mucho más a los Padres que los ministerios espirituales. Se pone mucho cuidado en ellas, porque cuando lo temporal y necesario al sustento va bien, todo lo espiritual va con mucho aumento y fervor (CARDIEL, [1771] 1994, p. 51).

El nuevo modelo económico diseñado para la misiones se proyectó sobre criterios occidentales de organización del tiempo y el espacio y en torno a concepciones particulares sobre el trabajo productivo, la acumulación y el bienestar. El trabajo pautado en horas y momentos, con fines concretos de subsistencia familiar y acumulación de excedentes para los depósitos comunales administrados por una estructura superpuesta, se constituyó en el eje de la nueva organización económica que generó tantas transformaciones como resistencias. Esto en gran medida por la persistencia de lógicas económicas que distanciaban notoriamente de aquellas que se buscaban imponer. Así pese a los diferentes medios desplegados por los jesuitas para generar adhesión al modelo de trabajo reduccional, tales como premios y castigos, no siempre lograron imponer sus ideales y ciertas formas de subsistencia se mantuvieron quizá como forma de resistencia. Al respecto, Cardiel afirmaba:

Si hay hambre u otro trabajo, no acude el indio a Dios y los Santos, como hace la gente de cultura y entendimiento, con devociones, y novenas, etc; sino que se huye a buscar que comer por los montes o matar vacas y terneras a los pastoreos o dehesas del común del pueblo, que llaman estancias (a las terneras tienen excesiva afición) y destruyen con eso al pueblo (CARDIEL, [1771] 1994, p. 51).

La dieta de los guaraníes en los tiempos prehispánicos incluía la carne obtenida por medio de la caza en el monte, aunque limitada por concepciones culturales que prevenían entre otras cosas la depredación. Bajo las reducciones continúo dicha práctica, bajo nuevos controles, el acceso a proteínas de origen animal provino fundamental de las reservas vacunas existentes en las estancias. Esta lógica alteró en extremo ciertas dinámicas y afinidades de 
obtención de recursos alimenticios, ya que los guaraníes muy adeptos a las raciones de carne obtenidas en las reducciones, optaban por no entregar mayor energía en las sementeras, ni al cuidado del ganado, que las previstas por de sus deseos y necesidades. Por eso es que solo tenían animales de forma comunal vigilados por la estructura administrativa misional ${ }^{10}$. Lo mismo sucedía con el intercambio comercial. Así si bien los guaraníes se sumaron a la dinámica del mercado, lo hicieron a través de sus lógicas propias o bajo el control político de los jesuitas.

El contraste entre modelos de comportamiento económico se hizo evidente en las reducciones y en algunos puntos hasta irresoluble. No ocurrió lo mismo con los oficios y las artes donde los misioneros mostraron estar conformes aunque solo aludieran a su capacidad para repetir o copiar las diferentes tareas enseñadas ${ }^{11}$. En lo que hace a la producción de bienes o alimentos, el modelo guaraní se distanciaba del occidental cristiano, europeo y misionero, entre otras cosas en que se basaba en el trabajo ritual y cooperativo, que perseguía un sistema de circulación y distribución reciprocitaria que respondía muchas veces a las necesidades inmediatas y festivas y a un concepto de bienestar cíclico que incluía la escasez como una instancia opuesta pero complementaria. Por su parte, la riqueza no era concebida en la acumulación de bienes, sino en la distribución y en su consumo en las fiestas. La acumulación de un cierto excedente tenía fines distintos a los concebidos en otras sociedades, ya que era pensada no para los tiempos de crisis sino para el consumo festivo. Por otra parte, no todas las actividades respondían a la subsistencia o al consumo, como era el caso de la caza. En torno a esta práctica existían un conjunto de valoraciones guerreras y de prestigio. Sin embargo, más allá de estos períodos extremos las necesidades cotidianas básicas solían estar cubiertas (SOUZA, 2002).

La idea de bienestar no era evidentemente compartida por guaraníes y jesuitas. $\mathrm{Al}$ respecto, mientras que para estos últimos respondía al patrón de racionalidad económica occidental, que incluir acumulación, previsión e inversión, en el universo de la cultura guaraní, concebida esta desde un punto de vista analítico, el bienestar se ponía en juego a través de la circulación de bebida y

Anos 90, Porto Alegre, v. 20, n. 37, p. 177-212, jul. 2013 
comida durante tareas y fiestas. Asimismo, conllevaba la posibilidad de su repetición en un tiempo cercano, como parte del fortalecimiento de redes políticas a través de la práctica del Don. Bajo el sistema misional jesuita, los guaraníes debieron no solo producir para otros que no fueran su familia nuclear o extensa, sino bajo lógicas muy distintas a las acostumbradas. Por ello fueron resistidas explícitamente, tanto en los espacios de producción familiar como comunal. Lo mismo ocurrió con los intercambios de bienes, ya que si bien estos eran supervisados por los jesuitas no faltaban los casos en los que los guaraníes trocaban productos en la campaña con sus vecinos los charrúas, los guenoas o los portugueses, con objetivos diversos. También eran comunes las entregas de carne a los portugueses en medio de enfrentamiento bélicos a cambio de favores o bienes diversos (QUARLERI, 2009). En todo ello, quedaba demostrado que a pesar de las políticas y los medios utilizados para su implementación los guaraníes reducidos encontraron espacios para continuar con ciertas prácticas dentro de lógicas resignificadas o adaptadas al contexto misional. En este sentido, las pautas de organización económica no encontraron un eco de transformación profundo y muchas de aquellas críticas elaboradas por los jesuitas fueron retomadas desde otra coyuntura y con otras motivaciones por aquellos funcionarios que oponiéndose al modelo de administración misionera pretendieron disolver el mismo para fomentar, en los guaraníes de los pueblos, la productividad y el intercambio individual. 


\section{De la comunidad de bienes al individualismo económico}

La expulsión de los jesuitas impuso nuevos desafíos a los pueblos de misiones y expuso los límites y alcances del modelo en relación a los diferentes ideales y paradigmas económicos y políticos que se fueron esbozando. En el Río de la Plata, el encargado de organizar la expulsión de los jesuitas fue el gobernador Francisco de Paula Bucareli y Ursúa (1766-1770) ${ }^{12}$. Un mes le llevó poner en práctica el decreto de expulsión en todos los colegios y estancias de la región y trasladar a los padres jesuitas a Europa. Sin embargo, en las treinta reducciones guaraníes el golpe político fue dilatado, ya que el gobernador tomó las prevenciones necesarias para evitar un levantamiento. ${ }^{13}$ Para ello, conformó un ejército dispuesto a hacer frente a una potencial rebelión y luego reunió bajo un ritual de solemnidad y pleitesía en Buenos Aires a los principales caciques de los pueblos y a sus corregidores. Durante seis meses colmó a más de cincuenta autoridades guaraníes allí presentes de hospitalidades y regalos. Además, les confirmó sus derechos a la tierra, los vistió a la española y reafirmó la prerrogativa de usar el "Don". El gobernador buscaba sentar las bases para reconstituir la relación de vasallaje con los caciques y los cabildos sin los jesuitas como intermediarios (WILDE, 1999 y 2003).

En las misiones guaraníes una nueva administración secular y religiosa se hizo cargo de los pueblos. En cada reducción se dispuso de dos religiosos de las Órdenes de Santo Domingo, San Francisco y La Merced y de un administrador laico ${ }^{14}$. A los guaraníes se les concedió el derecho de continuar nombrando a sus corregidores entre los caciques principales y mantener su cabildo como medio de gobierno interno, aunque supeditado al control del administrador secular. Se establecieron disposiciones generales sobre producción, trabajo, paga, posesión de bienes, comercio y residencia. Además, se introdujo la vestimenta española como obligatoria, la enseñanza del castellano por medio de escuelas con maestros laicos y se fomentó la unión de matrimonios mixtos dentro de una política de asimilación que se iría intensificando a lo largo de los años. Finalmente, se propició la relación directa entre los cabildos y el gobierno colonial para fortalecer los vínculos de 
los guaraníes con la administración central. Para ello, entre otras cosas, Bucareli confirmó funciones y otorgó cargos a los caciques que no gozaban de ellos y el uso de símbolos de prestigio tales como la vara y el bastón. De esta manera, durante su mandato, el gobernado recreó con las autoridades guaraníes un flujo de intercambios y contraprestaciones que buscaron reafirmaron la lealtad política de los mismos.

Desde el punto de vista económico el gobernador Francisco Bucareli y Ursúa buscó mantener ciertos aspectos de la organización jesuita previa y cambiar otros. Al respecto, ratificó en sus instrucciones la división entre los sistemas de producción familiar y comunal, así como la comercialización y distribución de los cultivos obtenidos de las siembras y plantíos comunes a través de la supervisión y aprobación de los diferentes niveles de gobierno, el cabildo, el administrador y el gobernador de misiones. Estas dos últimas figuras fueron introducidas dentro del nuevo régimen como medio de control y con el objeto de garantizar un buen gobierno, sin arbitrariedades y fraudes. La creación de un nivel de administración por encima o a la par del cabildo podía ser entendida como una forma de reemplazar las funciones realizadas por los jesuitas. Por otra parte, si bien si pretendía impulsar la autonomía económica de los pueblos, Bucareli como otros agentes coloniales consideraban que los indios no estaban aún en "aptitud" de cumplir adecuadamente con las lógicas de una producción eficiente y de asumir las reglas de un libre comercio libre. Por su parte, Bucareli sostuvo los almacenes de comunidad, la provisión de sustentos necesarios y vestuarios a los indios del común, así como la regulación del trabajo a través del control comunal del mismo ${ }^{15}$. Este régimen de producción, distribución y comercialización comunal con control político de la economía pasó a ser denominado por los funcionarios borbónicos como "sistema de comunidad", pasando a ser, como veremos, con los años criticado por un sector del gobierno colonial con fuertes argumentos contra los beneficios de su existencia en términos de la economía local y metropolitana.

Sin embargo, pese a las críticas posteriores Bucareli introdujo un conjunto de cambios en la organización económica y social de las misiones de guaraníes, inducido por paradigmas ilustrados en 
torno a los beneficios del comercio, la agricultura, la industria y el trabajo remunerado. En primer lugar, el incentivo al comercio constituyó la base y el principal eje de la intervención en los pueblos de misiones, ampliando el intercambio entre indios, españoles y entre las misiones y los centros urbanos próximos. No obstante, se privilegió a las ciudades de Santa Fe y Buenos Aires como destinos principales por la supuesta utilidad y ventaja de la venta de yerba, tabaco, azúcar, miel y lienzos en dichos puntos. Se autorizó la radicación de algunos españoles en las misiones y la entrega de casas y terrenos de cultivo para fomentar el comercio con los indios y para "animar" a estos últimos, con el ejemplo, "a la cultura de las tierras" ". Finalmente, entre otras cosas, se creó la administración general de misiones en Buenos Aires, a la cual se debía remitir el remanente de las ganancias comerciales luego de cubrir las necesidades de los pueblos y con la autorización y supervisión de los administradores, corregidores y mayordomos del cabildo. Su modelo estaba basado en la idea de que la productividad y los caudalosos ingresos imprimirían equidad y felicidad en el espíritu de los pueblos. En este sentido, Bucareli adhería a un concepto de abundancia ligado a la acumulación de bienes, como producto del "trabajo prolífero" y a la ocupación del tiempo de forma "productiva" y "civilizada". Así expresaba el gobernador sus ideas, en concordancia con paradigmas ideológicos de corte iluminista, sobre los aspectos mencionados:

El cultivo de las tierras es el segundo medio de que depende la adquisición de bienes temporales, y por lo mismo, pondrá usted especial cuidado en hacer conocer á los indios cuan útil les será este honrado ejercicio; que por tan interesante trabajo tendrán lo competente para sustentar á sus familias con abundancia; que, vendiendo los frutos que adquieran por medio de la cultura, se aumentarán en ella los caudales á proporción de las chacarerías, plantaciones y labores que hicieren; y que aquel, que hiciese más servicio al público en este fructuoso trabajo, se hará tanto más digno de las honras y empleos para que S. M. se ha servido habilitarlos. No omitiéndose, finalmente, diligencia alguna de introducir en 


\section{Lía Quarleri}

ellos aquella honesta y loable ambición que, desterrando de las repúblicas el pernicioso vicio de la ociosidad, las hace opulentas, principalmente, siendo estas tales, que su misma fertilidad estimula al trabajo en el seguro logro que promete. ${ }^{17}$

La condena al ocio, como sinónimo de uso del tiempo de forma improductiva, cobraba nueva fuerza en esta coyuntura pero mantenía casi el mismo significado que en los tiempos jesuitas. Por su parte en sintonía con el contexto y en relación a la doble concepción de los indios como sujetos limitados pero susceptibles a ser ilustrados en las artes de la industria, el comercio y la agricultura, por el poder de la instrucción y el adoctrinamiento, el gobernador consideraba que

Persuadidos los indios, por unos interesantes discursos, cuan útil les será el trabajo y perjudicial la ociosidad, procurará usted, por si y por medio de los administradores españoles, examinar para qué frutos es más á propósito el terreno de cada pueblo; conocimiento que de pronto se podrá adquirir, investigando de cuáles se acostumbraban hacer las chacarerías, así comunes, como particulares; é informado usted, determinará se verifiquen en mayor porción que antes las siembras y plantíos que son menos expuestos y á cuyo logro influye mejor el temperamento y terreno, teniendo presente que toda la felicidad de estos pueblos y de cualesquier otro país consiste en la abundancia de víveres necesarios a la conservación. ${ }^{18}$

Finalmente, la constante referencia al comercio como medio insoslayable para el engrandecimiento del estado, el progreso de los pueblos y la felicidad de la república quedaba una vez más detallada en las instrucciones de Bucareli. A su vez, si bien se reafirmaba la necesaria libertad de acción en el intercambio comercial se remarcaba en la necesidad de mediación por la falta de criterios adecuados al respecto por parte de los guaraníes. Este control político de la economía, que implicaba en cierto sentido una continuidad con el sistema jesuítico, constituirá una de las principales críticas que recibirá el modelo de Bucareli. 
En los años posteriores y pese al aumento de los ingresos por la comercialización de cueros y yerba a gran escala surgieron innumerables conflictos y ciclos críticos. Desde el punto de vista económico, los costos de producción aumentaron, así como las exigencias de prestación de fuerza de trabajo sobre los indios de común de los pueblos. Las prácticas clientelares se expandieron a todo nivel, dañando o resquebrajando especialmente las solidaridades al interior de los pueblos, aquellas que expresaron alianzas de intereses entre cabildos, curas, caciques y administradores en contra de la protección abusiva de su gente en el trabajo y de los bienes de comunidad. Al mismo tiempo, comenzó a producirse un avance de la sociedad criolla sobre el espacio de las misiones sin que se manifestase una política clara de defensa del territorio de los pueblos. Mientras que los pueblos más próximos al río Paraguay quedaron expuestos a los constantes ataques de los indios infieles chaqueños. En la década del setenta se sumó una coyuntura muy intensa de epidemias de viruela y sarampión que elevaron fatalmente las tasas de mortalidad. Finalmente, un ciclo de "fugas" y "evasiones", como de reclamos y motines, manifestaron diferentes mecanismos de resistencia activa contra la situación vivida en los pueblos (HERNÁNDEZ, 1999 y 2002; MAEDER 1992; SANTOS; BAPTISTA, 2007; SARREAL, 2008; SUSNIK, 1966).

Por su parte, desde el gobierno central se buscó imponer diferentes medidas para evitar el colapso económico, político y demográfico. Desde 1771 en adelante se ordenó reorientar el gobierno político y económico de los pueblos, que los administradores remitan los diezmos; alcabalas y tributos determinados en las instrucciones de Bucareli y que se cumpliesen con las normas de no despojar a los indios de sus tierras, bienes y casas. Para fines de la década de 1780, la preocupación por el destino de los pueblos y el pago de los impuestos aumentó considerablemente. Al respecto, en 1778 el Rey solicitó al gobernador de los pueblos de indios guaraníes, Francisco Bruno de Zabala:

[...]velar por las instrucciones de Bucareli especialmente en los capítulos que miran a la conservación de los indios, su agricultura, industria, uso de bienes y entera libertad en el manejo de ellos, en el tráfico y comercio de sus frutos, así 
en cuanto al comercio interno de los mismos pueblos o al general con los españoles o a los parajes o las que quieran traficarlos [...] para evitar todo fraude y perjuicio a los indios y procurar su utilidad y fomento de sus intereses [...] el buen gobierno de esta provincia y pública felicidad de los indios. ${ }^{19}$

Durante los años siguientes varias reglamentaciones fueron elaboradas para evitar los abusos, fraudes y negligencias generalizadas desplegadas sobre los indios y los pueblos, mientras las denuncias sobre los gobernadores, tenientes de gobernadores y administradores caían constantemente. Sin embargo nunca se cuestionó desde ningún sector los efectos del comercio y las exigencias generadas por el mismo, al contrario en el centro de los discursos siempre se lo idealizó como el medio indispensable para alcanzar el bienestar general.

Desde el lado de los guaraníes, las improntas del comercio a mayor escala y la explotación de la fuerza de trabajo habían comenzado a generar estratificaciones al interior de los pueblos. La marcada ausencia en los pueblos registrada durante las décadas posteriores implicó un conjunto diverso de respuestas que incluyó a familias extensas, a pequeños grupos o a individuos aislados. Diferentes estrategias se implementaron para evitar las cargas abusivas o para buscar nueva oportunidades, escapando de las epidemias y las muertes. La huída a la campaña misionera, a las tolderías de grupos infieles o las negociaciones con los corregidores para no ser nombrados en los padrones y censos y así quedar exentos de las cargas laborales oficiales, dentro y fuera de las misiones, fueron algunas de las respuestas desplegadas. El desplazamiento a centros urbanos de las jurisdicciones vecinas, puertos, estancias o las prestaciones de servicios como milicianos constituyeron otro conjunto de respuestas estratégicas en relación con las circunstancias. No obstante, las nuevas actividades y prácticas desplegadas fuera de las misiones en diferentes centros productivos, comerciales, artesanales, militares fueron generando deudas, obligaciones y nuevas relaciones, quedando los diferentes sujetos atados a los destinos elegidos (KÜHN, 2008; LANGER, 2005; SANTOS; BAPTISTA, 2007; WILDE, 2003 у 2007). La

Anos 90, Porto Alegre, v. 20, n. 37, p. 177-212, jul. 2013 
población de las reducciones a causa de muertes, ausencias, fugas o cambio de status fiscales se redujo, en tres décadas, a la mitad (MAEDER; BOLSI, 1982). Esto último sumado al deterioro edilicio y las disputas políticas entre los diferentes niveles de gobierno fueron conformando una imagen de decadencia generalizado frente al continuo reconocimiento de las potencialidades regionales. Esta contradicción fue explotada en sus informes por los funcionarios borbónicos enviados por la Corona, en la década de 1780, para cumplir con las consignas del flamante Tratado de Límites con Portugal ${ }^{20}$.

En esta oportunidad comisionados como Félix de Azara y Diego de Alvear en sus informes o historias naturales escritas en sus múltiples facetas de comisionados, expedicionarios y naturalistas repararon en el espacio misionero ${ }^{21}$. A estas narrativas se sumó a pedido de Azara la del Gonzalo de Doblas, teniente de gobernador del distrito misionero de Concepción. Lo que prevaleció en las relaciones de Azara, Doblas y Alvear fue una mirada que apuntaba a describir ciertos aspectos relacionados con los recursos naturales, la geografía y la población para luego presentar consideraciones centradas básicamente en las formas de revertir la situación de "decadencia" descripta para los pueblos guaraníes, sus tierras de cultivo y sus recursos ganaderos y con ello garantizar una explotación eficiente para las arcas del Estado. En sus escritos sobresalió su insistencia en la necesidad de desarticular el sistema de comunidad de bienes y adoptar en las misiones un sistema de libertad de comercio, posesión particular de bienes y acceso sin restricciones a la mano de obra de las reducciones, con el objeto implícito de dinamizar el mercado interno y los ingresos fiscales derivados. Con respecto al sistema de comunidad, Gonzalo de Doblas, teniente de gobernador de Concepción afirmaba que

Estos pueblos, desde su reducción, se han mantenido y mantienen en comunidad; y aunque este método de gobierno sería útil a los principios, después no ha servido en mi concepto sino a impedir los progresos de policía y civilidad: los que subsistirán desde mismo modo, entre tanto no se mude de gobierno, dando entera libertad a los indios como dicta la naturaleza (DOBLAS, [1785] 1970, p. 35).

Anos 90, Porto Alegre, v. 20, n. 37, p. 177-212, jul. 2013 


\section{Lía Quarleri}

Por su parte, Félix de Azara insistía en los elementos que habían condicionado el desenvolvimiento de la propiedad privada, el estímulo a la producción y al desarrollo de las capacidades individuales para alcanzar metas propias dentro de la lógica del utilitarismo de la época. Azara decía:

De esto se colige, que los padres curas eran árbitros de los fondos sobrantes de las comunidades de los pueblos, y que ningún indio podía aspirar a tener propiedad particular. Esto quitaba todos los estímulos de ejercitar la razón y los talentos; pues lo mismo había de comer, vestir y gozar el más aplicado, hábil y virtuoso, que el más malvado, torpe y holgazán (AZARA, [1809] 1941, p. 182-183).

Finalmente, Diego de Alvear dejaba entrever la necesidad de limitar o desarticular el régimen comunal misionero dando cuenta que en estas condiciones no daba rédito a la Corona. Alvear consideraba que:

Si damos ahora valor a la administración de justicia, teniendo los indios privilegios de menores, y gozando de entera libertad de derechos y costos en los tribunales del reino, y estimamos lo que puede valer la conservación y defensa de sus países en tiempos de guerra, veríamos que las misiones, en el píe que se hallan, son muy gravosas al estado, y que solo se mantienen para aumento de la cristiandad (ALVEAR, [1791] 1970, p. 721).

Las concepciones esbozas por estos tres sujetos solo daban cuenta de un paradigma que pronto cobraría protagonismo en la escena local en relación con las comunidades indígenas y que radicaba en la idea de asimilación de los indígenas a la sociedad local, en general, y por el otro, en la desarticulación lentamente del sistema de comunidad de bienes en los pueblos de misioneros, en particular. En el ámbito local y virreinal fuertes discusiones, 
en torno a la liberación de los indios de aquel sistema se suscitó entre 1799 y 1800 . Si bien estas ideas estaban presentes desde más de una década atrás fue con la llegada del Virrey Avilés, en 1798, que las mismas alimentadas por la ideología del liberalismo económico cobraron la forma de política reformista ${ }^{22}$. Esta última estaba también asociada a la expansión pobladora criolla, a una explotación racional de los recursos y a una concisa contribución de los territorios coloniales hacia la metrópoli. La idea era desvincular por etapas a ciertas familias del sistema de comunidad a través de la anulación de sus obligaciones laborales y a través de la adquisición de lotes de tierras para cultivo, animales, herramientas y alimento hasta un año (HERNÁNDEZ, 2002; SUSNIK, 1983). Los resultados fueron muy diversos ya que si bien la medida se decretó en 1800 para todos los pueblos de indios no se aplicó en todas las jurisdicciones afectadas. Con respecto a los guaraníes sus respuestas tampoco fueron unánimes y mientras algunos buscaron sumarse rápidamente al nuevo decreto, otros se opusieron, surgiendo incluso pugnas y conflictos al interior de los propios pueblos. La política de liberación de cargas y obligaciones no había contemplado la lógica que vinculaba económicamente a familias extensas y tampoco la disponibilidad de tierras fértiles en un contexto de avance hispano-criollo sobre los espacios circundantes.

La puesta en práctica de las nuevas medidas se complejizó con la coyuntura bélica que se abrió, a partir de 1801, tras la toma del territorio misionero del oriente del río Uruguay por los portugueses. Los rumbos fueron heterogéneos, hay quienes se quedaron en los pueblos en situaciones diversas y quienes salieron de los mismos para fundar nuevos asentamientos o para insertarse de forma familiar o individual en otros ámbitos rurales o urbanos, entrando en relación con otros sistemas de producción y trabajo. Las guerras de las independencias sumaron sustracción y caos en el territorio fronterizo donde habían estado localizados los pueblos de misiones y en consecuencia la discusión sobre el destino de los pueblos, su economía y política quedó desplazada de la escena discursiva y práctica. Dos siglos y medio de historia habían mostraron las diferentes facetas del colonialismo, en sus vertientes ideológicas y 
políticas. Con respecto puntualmente a los modelos económicos, además de los contextos específicos, las argumentaciones, que fueron justificando las diferentes reformas y medidas impuestas en relación con las poblaciones locales, cobraron un lugar destacado. Por su parte, desde el lado de los guaraníes tanto la adaptación estratégica como la resistencia, cotidiana o abierta, a las medidas económicas impuestas fueron mostrando de forma permanente los desfasajes y las contradicciones existentes entre las lógicas y concepciones de organización del trabajo, la acumulación de bienes y el bienestar comunal o familiar. Este entramado de ideologías y prácticas dejó expuesta la irracionalidad de las políticas del colonialismo que desde diferentes formas, medios y coyunturas siempre consideró desde un etnocentrismo acérrimo portar las ideas más elevadas e iluminadas para amoldar y encaminar el mundo a sus requerimientos.

\section{LOGICS AND CONCEPTIONS ABOUT WORK, ACCUMULATION AND WELFARE IN THE GUARANÍ INDIAN MISSIONS (17TH AND 18TH CENTURIES).}

Abstract: In this study seeks to show how were imposing in the missions of Guarani Indians a restructuring in the everyday practices of production, holding and movement of resources in intimate relationship with the European conceptions of work, productivity and well-being. It seeks to analyze the configuration of three models, the first of them centered on the opposition "desierto-abundancia", as a variable in the Jesuit period; the second is focalize on the change of an economy of reciprocity to the of an exchange of goods controlled under the reduction system and the latter in the contrast between the Community system and the regime of economic freedom, in the last decades of the colonial Government. The speeches of early chroniclers, Jesuits and officials Bourbon, will be the bases of this work, highlighting the tensions, transformations and also strategic responses of the Guarani families.

Keywords: Missions Guarani. Indigenous economy. Rio de la Plata. 
Lógicas y concepciones sobre trabajo, acumulación y bienestar en los pueblos...

\section{Notas}

${ }^{1}$ El referente más destacado ha sido, para al área andina colonial, Steve Stern. Para el área aquí estudiada no puede dejar de mencionarse a Branislava Susnik. Si bien ambos autores formaron parte de corrientes teóricas y formaciones diferentes, ambos hicieron hincapié en las acciones indígenas en su complejidad histórica.

${ }^{2}$ Representantes de estas líneas teóricas son Serge Gruzinski y Carmen Bernand, entre otros.

${ }^{3}$ Cabe aclarar que el modelo de cambios proyectado tuvo mayor expresión en el plano del discurso y las ideas que en el de las prácticas donde hubo lugar en algunos aspectos de la vida cotidiana para la negociación o la disrupción del sistema normativo impuesto desde la Orden.

${ }^{4}$ Cabe mencionar que la guerra ocupaba un lugar destacado en estas sociedades y estaba asociado a prácticas colonizadoras, alianzas políticas, cosmovisiones y valores culturales determinados. Por su parte las aldeas estaban protegidas y vigiladas de forma permanente ante un potencial ataque enemigo (QUARLERI, 2009).

${ }^{5}$ Los guaraníes solían hacerse de esclavos de otras comunidades o grupos étnicos en virtud de entramados conceptuales asociados a la venganza y a la rivalidad bélica y no como una acción premedita para sumar brazos a la agricultura, la caza o la pesca.

${ }^{6}$ Los términos de estas alianzas han sido analizados extensamente en los clásicos trabajos de Branislava Susnik (1979 y 1983), luego de Florencia Roulet (1992 y 1993) y más recientemente de Macarena Perusset (2008), entre otros.

${ }^{7}$ En el contexto de la conquista de América en algunas regiones de España existía la distinción entre hidalgos o nobles y pecheros o comuneros que pagaban tributo al primero. Esta distinción se fue difuminando en la América española y trasladándose a la sociedad hispano-indígena (ALTMAN, 1988).

${ }^{8}$ José Otávio Catafesto de Souza (2002) en su trabajo O sistema econômico nas sociedades indígenas guarani pré-coloniais analiza extensamente las características de la economía doméstica guaraní, en relación con los principios de su organización comunal a la luz de las grandes teorías de la antropología económica. El autor da cuenta de las diferencias entre las economías basadas en el don y en aquellas basadas en el lucro; al mismo tiempo que discute las conceptualización elaboradas desde la economía clásica en donde se cuestiona a las organizaciones basadas en la producción doméstica la ausencia de capacidad excedentaria y la vulnerabilidad frente a las crisis por sequías, epidemias, plagas o inundaciones.

${ }^{9}$ Los altos costos de mantenimiento de la grandeza jesuita han sido estudiados previamente, asimismo como los conflictos internos entre los jesuitas de diferentes provincias por la distribución de ciertos bienes e ingresos derivados por ejemplo de donaciones de particulares (QUARLERI, 2003 y 2005).

Anos 90, Porto Alegre, v. 20, n. 37, p. 177-212, jul. 2013 


\section{Lía Quarleri}

${ }^{10}$ José Cardiel comentaba que "Los indios no tienen en particular vacas, ni bueyes, ni cabalos, ni ovejas, ni mulas: sino gallinas porque no son capaces de más" (CARDIEL [1771], 1994, p. 54).

${ }^{11}$ Antonio Sepp decía "Ya nuestros antecesores han enseñado a esta gente, por lo demás muy tonta, pero muy hábil para remedar, no solo la religión cristiana, sino también a hacer pan y comida y vestido, a pintar, a fundir campanas, a fabricar órganos e instrumentos musicales y relojes; en una palabra todas las artes y oficios de Europa, principalmente la música como parte esencial del divino servicio, aunque no con la perfección acabada en Europa, pero bastante bien" (SEPP, [1732] 1962, p. 23).

${ }^{12}$ Las órdenes secretas dictadas por el Rey contemplaban la deportación de los religiosos a los Estados Pontificios de Italia y la incautación de los bienes muebles e inmuebles que habían estado bajo administración de la Compañía de Jesús. Luego de la expulsión, los bienes de los jesuitas adquirieron el nombre de "temporalidades". Su administración o transferencia, a través de la comercialización de la producción y del arriendo o de la venta de los bienes en el caso de las haciendas, fue encargada a Juntas y Comisionados sobre los que recayeron no pocas denuncias de malversación. Este proceso se extendió hasta principios del siglo XIX (MAEDER, 2001).

${ }^{13}$ Entre los años 1753 y 1756 se había suscitado un enfrentamiento inédito entre las misiones del Uruguay y el poder real, por la defensa del territorio reduccional, que terminó con la derrota bélica de los pueblos. El miedo a otro levantamiento estaba presente entre las autoridades coloniales en el contexto de la expulsión de los jesuitas (QUARLERI, 2009).

${ }^{14}$ Tras la expulsión de los jesuitas, las treinta reducciones se mantuvieron bajo un mismo régimen divididos en dos distritos, el de Paraná y el de Uruguay, dentro de la jurisdicción de Buenos Aires. La designación de dos gobernadores duró solo un año, ya que a partir de 1769 se mantuvo uno solo de ellos y se nombraron tres tenientes de gobernador. En 1774 se crearon nuevas agrupaciones llegando a estar los pueblos supeditados a los departamentos de Santiago, San Miguel, Yapeyú, Concepción y Candelaria. Con la Real Ordenanza de Intendentes Concepción y Candelaria pasaron a depender del Paraguay y los otros tres departamentos a Buenos Aires. El giro y cambio estructural se produjo en 1801 con la ocupación del departamento de San Miguel, al este del río Uruguay por Portugal, y luego con el impacto general que produjeron sobre este territorio las guerras independentistas (MAEDER, 1992; POETNIZ; POETNIZ, 1998). 15 “Instrucción a que se deberán arreglar los Gobernadores interinos que dejo nombrados en los pueblos de indios guaraníes del Uruguay y Paraná, no habiendo disposición contraria de Su Majestad. Francisco Bucareli y Ursua, Candelaria, 23 de agosto de 1768". Colección de Documentos relativos a la expulsión de los jesuitas

Anos 90, Porto Alegre, v. 20, n. 37, p. 177-212, jul. 2013 
Lógicas y concepciones sobre trabajo, acumulación y bienestar en los pueblos...

de la República Argentina y del Paraguay, en el Reinado de Carlos III. Introducción y notas de Francisco Javier Bravo, Madrid, Establecimiento Tipográfico de José María Pérez, 1872.

16 "Instrucción a que se deberán arreglar los Gobernadores interinos...", op cit., p. 208.

17 "Instrucción a que se deberán arreglar los Gobernadores interinos...", op cit., p. 202-203.

18 "Instrucción a que se deberán arreglar los Gobernadores interinos...", op cit., p. 204.

19 "Reglas para el mejor gobierno de los guaraníes, El Rey, 5 de octubre de 1778". Archivo General de la Nación, Buenos Aires (AGN). Sala 7, Colección Biblioteca Nacional, Documento 5065, fojas 4v-5.

${ }^{20} \mathrm{El}$ Tratado de San Ildefonso fue firmado en 1777 para dirimir una vez más los límites conflictivos entre España y Portugal en sus fronteras coloniales.

${ }^{21}$ Las múltiples facetas de estos funcionarios y sus concepciones sobre el espacio misionero fueron estudiadas previamente en QUARLERI (2011).

${ }^{22}$ Las bases de esta nueva política quedaron expuestas en los informes escritos por el Secretario del Virrey Avilés, Miguel de Lastarría.

\section{Referencias}

ALTMAN, Ida. Emigrants and Society: An Approach to the Background of Colonial Spanish América. Comparative Studies of Society and History, v. 30, n. 1, 1988.

ALVEAR, Diego. Relación Geográfica e Histórica de Misiones. In: Pedro de Angelis (comp.). Colección de obras y documentos relativos a la historia antigua y moderna de las provincias del Río de la Plata. Buenos Aires: Editorial Plus Ultra, 1970, p. $579-727$.

AZARA, Félix. Viajes por la América Meridional. Madrid: Espasa-Calpe, 1941.

BRUXEL, Arnaldo. O sistema de propriedades das reduções guaraníticas. Pesquisas, n. 3, p. 29-145, 1959.

CARBONELL DE MASY, Rafael. Estrategias de desarrollo rural en los pueblos guaranies (1609-1767). Barcelona: Sociedad Estatal Quinto Centenario, 1992a.

La propiedad comunitaria en las reducciones jesuíticas guaraníes. Suplemento Antropológico, n. 27, v. 2, p. 99-130, 1992b.

CARDIEL, José S. J. Breve Relación de las misiones del Paraguay. Buenos Aires: Ediciones Teoría, 1994.

CHAMORRO, Graciela. Teología guaraní. Quito: Ediciones Abya-Yala, 2004.

Anos 90, Porto Alegre, v. 20, n. 37, p. 177-212, jul. 2013 


\section{Lía Quarleri}

COLECCIÓN DE DOCUMENTOS relativos a la expulsión de los jesuitas de la República Argentina y del Paraguay, en el Reinado de Carlos III. Introducción y notas de Francisco Javier Bravo. Madrid: Establecimiento Tipográfico de José María Pérez, 1872.

DOBLAS, Gonzalo de. Memoria sobre la Provincia de Misiones de indios Guaranies. In: Pedro de Angelis (comp.). Colección de obras y documentos relativos a la historia antigua y moderna de las provincias del Río de la Plata. Buenos Aires: Editorial Plus Ultra, 1970, p. 23-187.

FURLONG, Guillermo SJ. Misiones y sus pueblos guaranies. Buenos Aires: Imprenta Balnes, 1962a.

1962b.

. Antonio Sepp, S. J. Y su "gobierno temporal" (1732). Buenos Aires: Ed. Theoria,

GADELHA, Regina. As Missões Jesuíticas do Itatim. Estructuras Socioeconômicas do Paraguai colonial Seculos XVI e XVII. Río de Janeiro: Paz e Terra, 1980.

GARAVAGLIA, Juan Carlos. Economía, sociedad y regiones. Buenos Aires: Ed. de la flor, 1987.

Un modo de producción subsidiario: la organización económica de las comunidades guaranízadas durante los siglos XVII-XVIII en la formación regional altoperuano-rioplantense. In: Assadourian, Carlos, et. al. (comps). Modos de Producción en América Latina. Cuadernos de Pasado y presente. México: Siglo XXI, 1984.

HERNÁNDEZ, Juan. Tumultos y motines. La conflictividad social en los pueblos guaraníes de la región misionera (1768-1799). Memoria Americana, n. 8, p. 83-100, 1999.

."Las reformas del virrey Aviles en los pueblos guaraníes de Misiones (1799-1801)". Prohistoria, n. 1, 2002.

HERNÁNDEZ, Pablo. Organización social de las Doctrinas Guaranies de la Compañia de Jesús. Barcelona: Gustavo Gilli, 1913.

KÜHN, Fabio. “O 'goberno dos indios': Notas sobre a populacão da aldeia guarani-missioneira de Nossa Senhora dos Anjos (1770-1779)". In: XII Jornadas Internacionales sobre las misiones jesuiticas: "Interacciones y sentidos de la conversión". Manzana de las Luces, Buenos Aires, 2008.

LANGER, Protasio. Os Guarani-missioneiros e o Colonialismo Luso no Brasil meridional. Projetos Civilizatórios e Faces da Identidade Étnica (1750-1798). Porto Alegre: Editor Martins Livreiro, 2005.

LEVINTON, Norberto. Las estancias de Nuestra Señora de los Reyes de Yapeyú: Tenencia de la tierra por uso cotidiano, acuerdo interétnico y derecho natural (misiones jesuíticas del Paraguay). Revista Complutense de Historia de América, n. 31, p. 33-51, 2006.

Anos 90, Porto Alegre, v. 20, n. 37, p. 177-212, jul. 2013 
Lógicas y concepciones sobre trabajo, acumulación y bienestar en los pueblos...

MAEDER, Ernesto. Expansión y contracción del espacio misionero. Las estancias de los pueblos guaraníes (1700-1810). GAEA, n. 19, p. 139-153, 1997.

- Los bienes de los jesuitas. Destino y administración de sus temporalidades en el Rio de la Plata 1767-1813. Resistencia: CONICET. Instituto de Investigaciones Geohistóricas, 2001.

PFRE: Madrid, 1992.

Misiones del Paraguay: conflicto y disolución de la sociedad guaraní. MA-

MAEDER, Ernesto; BOLSI, Alfredo. "La población guaraní de la provincia de misiones en la época post-jesuítica (1768-1809)". Folia Histórica del Nordeste, n. 5, p. 61-106, 1982.

MELÍÁ, Bartomeu. La tierra sin mal de los guaranís. Economía y profecía. Suplemento Antropológico, n. 22, v. 2, p. 81-98, 1987.

. Potirö: la forma de trabajo entre los Guaraní antiguos "reducidos" y modernos. Revista Complutense de Historia de América, n. 22, 1996.

MELÍÁ, Bartomeu; TEMPLE, Dominique. El don, la venganza y otras formas de economía guaraní. Asunción: Centros de Estudios Paraguayos, 2004.

MÖRNER, Magnus. Actividades politicas y económicas de los jesuitas en el Río de la Plata. Buenos Aires: Hyspamérica ediciones, 1986.

NECKER, Louis. Indios guaranies y chamanes franciscanos. Las primeras reducciones del Paraguay (1580-1800). Asunción, Biblioteca Paraguaya de Antropología, Centro de Estudios Antropológicos, Universidad Católica, 1990.

NEUMANN, Eduardo. O trabalho guarani missioneiro no Rio da Prata Colonial, 16401750. Porto Alegre: Martins Livreiro, 1996.

PERUSSET, Macarena. Guaraníes y españoles. Primeros momentos del encuentro en las tierras del antiguo Paraguay. Anuario del Centro de Estudios Históricos "Prof. Carlos S. A. Segreti”, n. 3, Año 8, p. 245-264, 2008.

POETNIZ, Edgar; POETNIZ, Alfredo. Misiones, Provincia Guaranítica. Defensa y Disolución (1768-1830). Editorial Universitaria: Posadas, 1998.

POPESCU, Oreste. Sistema económico en las misiones jesuiticas: un vasto experimento de desarrollo iberoamericano. Barcelona, Ariel, 1967.

QUARLERI, Lía. Autonomía local y Buen Gobierno: Jesuitas contra jesuitas en la provincia del Paraguay. Cuadernos de Historia: Serie Economía y Sociedad, n. 7, p. 153-186, 2005.

- Expediciones, narrativas y utopías Nuevas miradas sobre el "espacio guaraní-misionero” (1784-1796) ANTITESIS, v. 4, n. 8, 2011 (En prensa).

Anos 90, Porto Alegre, v. 20, n. 37, p. 177-212, jul. 2013 


\section{Lía Quarleri}

QUARLERI, Lía. Los Jesuitas en Córdoba y La Rioja. Construcción de poder y diferenciación y manifestaciones de oposición y resistencia en la interacción social. Tesis doctoral. Facultad de Filosofía y Letras, Universidad de Buenos Aires, 2003.

Rebelión y guerra en las fronteras del Plata. Guaranies, jesuitas e Imperios coloniales.

Fondo de Cultura Económica: Buenos Aires, 2009.

ROULET, Florencia. Fragmentación política y conflictos interétnicos. Las condiciones internas de la vulnerabilidad de los guaranís antes de la conquista española. Suplemento Antropológico, n. 1, v. 27, p. 159-186, 1992.

La resistencia de los guaranies del Paraguay, a la conquista española (1537-1556). Posadas: Universidad Nacional de Misiones, 1993.

RUIZ DE MONTOYA, Antonio. La Conquista Espiritual del Paraguay. Hecha por los religiosos de la Compañia de Jesús en las provincias del Paraguay, Paraná, Uruguay y Tape. Rosario: Equipo Difusor de Estudios de Historia Iberoamericana, 1989.

SANTOS, María Cristina; BAPTISTA, Jean Tiago. Reduções jesuíticas e povoados de índios: controvérsias sobre a população indígena (séc. XVII-XVIII). Historia UNISINOS, n. 11, v. 2, p. 240-251, 2007.

SARREAL, Julia. "Los guaraníes y el colapso del régimen comunitario de las misiones, 1768-1800”. In: XII Jornadas Internacionales sobre las Misiones Jesuiticas: Interacciones y sentidos de la conversión. Manzana de las Luces, Buenos Aires, 2008. . Disorder, wild cattle, and a new role for the missions the Banda Oriental, 1776-1786. The Americas, n. 4, v. 67, p. 517-545, 2011.

SCHMIDL, Ulrico. Viaje al Río de la Plata. Buenos Aires: Emecé, 1997.

SEPP, Antonio S. J. Antonio Seppy su “Gobierno Temporal”. Buenos Aires: Ediciones Teoría, 1962.

SOUZA, José Otávio Catafesto de. O sistema econômico nas sociedades indígenas guarani pré-coloniais. Horizontes Antropológicos, ano 8, n. 18, p. 211-253, 2002.

SUSNIK, Branislava. El indio colonial del Paraguay. Tomo II. Asunción: Museo Etnográfico "Andrés Barbero", 1966.

. El Rol de los Indígenas en la Formación y en la Vivencia del Paraguay. Tomo II. IPEN. Asunción: Editorial Universo, 1983

- Etnohistoria de los guaraníes. Época Colonial. "Los Aborígenes del Paraguay”. Tomo II. Asunción: Museo Etnográfico “Andrés Barbero”, 1979-1980

- La cultura indígena y su organización social dentro de las misiones jesuíticas. Suplemento Antropológico, n. 19, v. 2, p. 7-19, 1984.

Anos 90, Porto Alegre, v. 20, n. 37, p. 177-212, jul. 2013 
Lógicas y concepciones sobre trabajo, acumulación y bienestar en los pueblos...

VIVEIROS DE CASTRO, Eduardo. Perspectivismo y Multinaturalismo en la América Indígena. In: SURRALLÉS, Alexandre; HIERRO; Pedro García (eds.). Tierra adentro. Territorio indígena y percepción del entorno. Copenhague: IWGIA, p. 3780, 2004.

WILDE, Guillermo. Antropología histórica del liderazgo guaraní misionero (17501850). Tesis doctoral. Facultad de Filosofía y Letras. Universidad de Buenos Aires, 2003.

- De la coacción a las estrategias. Algunas reconsideraciones del modelo jesuítico guaraní. Razón y Revolución, n. 7, p. 111-124, 2001 a.

Estrategias indígenas y límites étnicos. Las reducciones jesuíticas del Paraguay como espacios socioculturales permeables". Anuario IEHS, n. 22, p. 213$240,2007$.

. La actitud guaraní ante la expulsión de los jesuitas. Ritualidad, reciprocidad y espacio social. Memoria Americana, n. 8, p. 141-172, 1999.

. Los guaraníes después de la expulsión de los jesuitas. Dinámicas políticas y prácticas simbólicas". Revista Complutense de Historia de América, n. 27, p. 69-109, 2001b.

2009.

. Religión y poder en las misiones de guaranies. Buenos Aires: SB Ediciones,

Recebido em: 07/03/2012

Aprovado em: 05/04/2012

Anos 90, Porto Alegre, v. 20, n. 37, p. 177-212, jul. 2013 